\section{Questión}

Periodismo / Comunicación

ISSN 1669-6581

Comunicación y Sentido Común en sociedades latinoamericanas

Gabriel Alejandro Villalba Pérez

Question/Cuestión, Vol. 2, N66, Agosto 2020

ISSNe 1669-6581

https://perio.unlp.edu.ar/ojs/index.php/question/index

IICom-FPyCS-UNLP

DOI: https//doi.org/10.24215/16696581e463

\title{
Comunicación y sentido común en sociedades
} latinoamericanas

\section{Communication and common sense in latin american societies}

Gabriel Alejandro Villalba Pérez Centro de Estudios Nuestroamericano Bolivia, Estado Plurinacional de Bolivia

gabrielvillalbap@gmail.com https://orcid.org/0000-0001-7828-6043

\section{Resumen}

Las nociones sobre Sentido Común y Sociedades Democráticas se abordan desde elementos comunicacionales que permiten interpretar la realidad social multidimensionada, deconstruirla, proponer su reconfiguración y articular la Comunicación como fuente de transformaciones sociales. Se desarrolla una 
diferenciación de matrices, abordajes y enfoques comunicacionales que permiten entender cada elemento comunicacional en función a metas y objetivos concretos de orden cuantitativo y cualitativo. Se proponen estrategias de gestión comunicacional inherentes a las diversas formas de organización popular que permiten perfeccionar la participación democrática a través de elementos comunicacionales, entendiendo que el Sentido Común de las sociedades se encuentra en permanente disputa, construcción y reconfiguración en torno al sentido de época y los momentos históricos particulares. Se brindan nociones de interpretación de la realidad social latinoamericana a partir de la Comunicación, pero también propuestas de transformación entendiendo que las sociedades latinoamericanas son heterogéneas muy diferentes a las sociedades europeo continentales y a las anglosajonas. La Comunicación es enfocada a través de sus estrategias comunicacionales como primaria para la interpretación y transformación social, no así accesoria como se teoriza desde el Pensamiento Crítico. A la vez, todo el trabajo devela que no son únicamente los medios hegemónicos de comunicación ni exclusivamente los políticos los únicos actores constructores de Sentido Común en las sociedades.

\section{Palabras clave}

Comunicación Política, Sentido Común, Latinoamérica

\section{Abstract}

The notions about Common Sense and Democratic Societies are approached from communicational elements that allow interpreting multidimensional social reality, deconstructing it, proposing its reconfiguration and articulating Communication as a source of social transformation. A differentiation of 
matrices, approaches and communicational approaches is developed that allow understanding each communicational element based on specific goals and objectives of a quantitative and qualitative order. Communication management strategies inherent to the various forms of popular organization are proposed that allow to improve democratic participation through communicational elements, understanding that the Common Sense of societies is in permanent dispute, construction and reconfiguration around the sense of time and the particular historical moments. Notions of interpretation of Latin American social reality are provided from the Communication, but also proposals for transformation, understanding that Latin American societies are heterogeneous and very different from continental European and Anglo-Saxon societies. Communication is focused through its communicational strategies as primary for interpretation and social transformation, not as accessory as it is theorized from Critical Thinking. At the same time, all the work reveals that it is not only the hegemonic means of communication, nor exclusively the politicians, the only common sense-building actors in societies.

\section{Key Words}

Political Communication, Common Sense, Latin America

\section{Introducción}

Abordar las problemáticas políticas y comunicacionales en sociedades democráticas heterogéneas, como las latinoamericanas, plantea un dilema en el abordaje. La tradición comunicacional anglosajona se cruza con las corrientes desarrolladas desde Latinoamérica, con todas las particularidades socioculturales inherentes al desarrollo histórico, político, social y cultural. La 
Comunicación debe adentrarse en el entramado social y brindar soluciones desde las aristas multidimensionales de la estrategia y gestión comunicacional que permitan develar los entramados sociales de sentidos y contrasentidos que se disputan en la construcción de las lógicas sociales.

La ciencia de la Comunicación a través de sus diferentes elementos comunicacionales aborda diversas dimensiones de la cotidianidad social. Mismos que sirven para comprender y develar el sentido de las relaciones sociales, la interpretación de valores y la construcción de nuevos sentidos en las sociedades. A partir de las inter relaciones políticas y sociales transversalizadas por la comunicación se genera Sentido Común (1) desde la construcción de hegemonía legitimada por los procesos comunicacionales de participación activa y horizontal.

El campo de la Comunicación permite interpretar las dimensiones relacionadas con la construcción de significantes, de empoderamiento en sus múltiples interpretaciones, construcción de sentidos y consolidaciones sociales a partir de elementos comunicacionales que permiten transformar una realidad social determinada, generando nuevos imaginarios colectivos que a su vez disputen y construyan el Sentido Común imperante en determinado momento histórico de las sociedades democráticas

La gestión de los elementos comunicacionales debe permitir analizar desde la Comunicación una forma dinámica de entender la realidad social y sus múltiples espacios de composiciones. Desde una perspectiva de totalidad no fraccionada, transversalizada por las lógicas comunicacionales, se deben comprender, develar y reconfigurar las relaciones de poder, significantes, sentidos, saberes, discursos y derechos. 
La Comunicación en la construcción del Sentido Común debe abordarse desde el entendimiento multidimensional de la sociedad. La noción de Sociedad Democrática en sintonía comunicacional no solamente se comprende desde la dogmática jurídica o teoría política del "Estado de Derecho". Bolivia se constituye en un Estado Social de Derecho (2) por ende una sociedad que garantiza constitucionalmente no sólo los derechos civiles y políticos de primera generación, sino también los derechos civiles, políticos, económicos, sociales y culturales enmarcados en el paradigma de un Estado Social, Democrático y Constitucional de Derecho (3).

La lógica de la Comunicación en sociedades democráticas, interviene en los distintos actores individuales y colectivos que generan en sus inter relaciones procesos, comportamientos discursivos y argumentativos de orden político, así como sus relaciones sociales dentro del esquema democrático del Estado Social, Democrático y Constitucional de Derecho.

En este marco la gestión comunicacional comprende fenómenos situacionales complejos y fluidos. El abordaje teórico de la Comunicación Estratégica se adscribe en una "dimensión del tiempo como experiencia, la complejidad de la comunicación en tanto construcción inter subjetiva de la temporalidad en y a través de los signos y de las emociones como un auto dispositivo colectivo" (Massoni, 2011, p. 25). La Comunicación Estratégica abordada por esta autora fundamenta la interpretación de nuevos planos sociales que permitan emerger nuevas realidades, a través, precisamente, de la comprensión y desarrollo de las nociones de Sentido Común y Sociedad Democrática. 


\section{Desarrollo}

La interpretación y el análisis de la realidad social para su transformación a partir de la Comunicación parte de la diferenciación y clara distinción de los abordajes comunicacionales, siendo estos fundamentales, en su distinta aplicación, para plantear todo proceso de gestión de la comunicación en clave latinoamericana.

La Comunicación aporta, a partir de su entendimiento lógico y teórico, nociones para las nuevas formas de organización popular urgentes en procesos políticos, sociales y culturales. Los ejes teóricos a ser entendidos y abordados plantean diversos caminos de abordajes comunicacionales, el desarrollo histórico y propio en sus particularidades, de la comunicación latinoamericana y las diversas formas de organización popular desde la construcción de consensos y ulterior generación de hegemonía devenida de necesidades modernas de las sociedades democráticas latinoamericanas.

El ámbito de la gestión comunicacional deviene del entendimiento teórico conceptual de las nociones y teorías que conglomeradas plantean, en diferentes líneas, la transformación social. Estas nociones son las siguientes:

\section{Diferenciaciones comunicacionales para el abordaje de la interpretación social}

Las matrices de la comunicación se estructuran en corrientes con distintos criterios de organización, que cuentan con un esquema aceptado comúnmente para el proceso comunicativo:

Emisor $\rightarrow$ Mensaje $\rightarrow$ medio $\rightarrow$ receptor En un determinado C.S.

Proceso que ocurre en determinadas condiciones sociales: el Contexto Social (C.S.) 
La teoría del proceso comunicativo se presenta como la conceptualización de una práctica. La base de la práctica comunicacional es el uso de signos como materia prima. Ya que son los signos los que producen significados. Convirtiendo lo real en teoría. En la teoría marxista se desarrollaría de esta forma:

Concreto Real $\rightarrow$ Concreto Representado $\rightarrow$ Concreto Pensado

Como punto de partida; imagen mental; Conceptual; Objeto comprendido Los abordajes de la comprensión del proceso comunicativo se desarrollan desde tres grandes perspectivas; el pragmatismo ligado íntimamente a la teoría de los efectos. La teoría critica que comprende precisamente la crítica a la teoría pragmática desde la construcción de la ideología. Y el abordaje crítico utópico de la comunicación con teóricos latinoamericanos que desarrollan las concepciones de democracia y participación fundamentalmente.

El enfoque pragmático de la comunicación surge el siglo XIX en EE.UU. e Inglaterra desde el utilitarismo: la teoría tiene que ser algo útil, o no sirve. La utilidad se convierte en el centro del conocimiento. Lo útil se presenta como lo verdadero. Se persiguen resultados concretos en el proceso de la comunicación. La lógica comercial de los medios de comunicación gira en torno a este paradigma y forma unidireccional de desarrollar la Comunicación.

Le enfoque pragmático, por otro lado, se desarrolla principalmente en Europa continental como un cuestionamiento de la realidad, de los hechos concretos. Cuestionando la realidad tal cual se la percibía. Se critica la matriz civilizatoria y por ende se prepondera la ideología cuestionando la alienación como el encubrimiento de lo real. Se cuestiona, critica y estudia el pensamiento dominante para deconstruirlo. Se critica la industria cultural, las formas de alienación cultural y la plusvalía ideológica para vislumbrar una propuesta de 
emancipación que no deja de ser unidireccional, pero en contrasentido a la teoría pragmática.

El enfoque crítico utópico plantea un diseño para el futuro rescatando la teoría crítica europea, se constituye en una guía de acción y propuesta de cambio. Diseñando desde la utopía una sociedad democrática y altamente participativa. La Comunicación se constituye como un proceso de ida y vuelta quebrando con el unidireccionalismo. Pero a la vez intentando rescatar casi eclécticamente lo mejor de la teoría pragmática en lo cuantitativo, medible y científico. Y por otro lado los estudios culturales con la preponderancia de las construcciones ideológicas. La comunicación y la cultura de masas se entremezclan con propuestas que se conjugan proyectando enfoques de estudios comunicacionales tales como la ideología dominante, propiedad de los medios de comunicación, control de los medios, mundialización cultural, entre otros.

En su desarrollo histórico la Comunicación ha sido conceptualizada desde los enfoques mencionados precedentemente, pero con una misma línea argumentativa muy ligada a la construcción cultural hegemónica denominada "occidente", posicionada como generadora del monopolio del conocimiento. Aristóteles con referencia a la "retórica" es instrumentalizado por la comunicología para esbozar tres elementos de la ciencia de la comunicación: locutor, discurso y oyente. Siendo una de las primeras definiciones. La historia occidental seguirá conceptualizando e incorporando elementos en la teorización del proceso comunicacional.

La definición tradicional de Comunicación deviene de la preocupación por los efectos del mensaje en el receptor, una visión unidireccional y vertical. La teoría de la comunicación de masas (McQuail, 1985, p. 79) refuerza esa visión estratificada e impersonal del proceso comunicacional convencional. Los 
teóricos pragmáticos (4) representantes de lo que se denomina "occidente" refuerzan un sistema de conocimientos basado en los resultados, la manipulación de las masas y los efectos esperados en función a estrategias pre diseñadas que conciben un solo sujeto pensante, el emisor del mensaje.

La Comunicación horizontal como nuevo paradigma y en contraposición a la construcción de Comunicación "occidental" genera premisas básicas de interrelación desde la lógica ambivalente de comunicar. Enfatiza la capacidad de recibir mensajes comunicados por el otro, rompe la lógica de jerarquización y plantear relaciones horizontales que implican una real democratización en la relación comunicacional.

La visión crítica (Althusser, 1988, p. 99) esboza un pensamiento de interpelación a los métodos heredados desde "occidente" para estudiar y desarrollar la Comunicación. Además de la preponderancia cultural y, en el caso de Louis Althusser, política, para comunicar con sentido de reflexión y organización en pos de una transformación social. Las adopciones foráneas reforzaron la visión anglosajona y europea de los procesos comunicacionales, muy conveniente para sus realidades sociales y los momentos históricos específicos de su desarrollo, pero anacrónica a una realidad social y política como la de las sociedades democráticas latinoamericanas.

La comunicación horizontal (Beltrán, 1982, p. 117) como teorización no deconstruye totalmente la versión vertical de comunicación, resalta sus virtudes operativas y prácticas para incorporarlas en matrices comunicacionales particulares. Prepondera la visión democrática participativa de la teoría crítica adecuándola a la realidad latinoamericana. No constituye absolutismos, ni tampoco eclecticismo, sino un marco teórico conceptual de orden utópico que plantea como horizonte la participación desde donde se genera la 
comunicación, que es la propia sociedad; permeada por sus valores culturales, costumbres, formas, significantes e inter-relacionamiento simbiótico de todos estos elementos en planos multidimensionales.

\section{Gestión comunicacional a partir del desarrollo histórico de la Comunicación en Latinoamérica}

Las sociedades latinoamericanas en su propio desarrollo teórico comunicacional fueron influenciadas por el marxismo europeo y el posterior marxismo heterodoxo perfeccionado en el continente. La comunicación latinoamericana se desarrolló con un horizonte de crítica a lo establecido, de repudio a las formas de dominación; intentando tematizarlas a partir de enfoques que no devenían exclusivamente de la Comunicación, tal es el caso de la instrumentalización de Louis Althusser para explicar ciertos fenómenos de dominación, oposición a lo hegemónico y propuesta de un sentido subalterno (Althusser, 2016, p. 64). Este autor no se refiere específicamente a lo comunicacional, sino a lo ideológico político, pero constituye una influencia importante para empezar a proponer una gestión de la comunicación a partir de su desarrollo teórico en el campo de la Ciencia Política. El patrón común en estos aportes es la resistencia y crítica de lo hegemónico, del sentido dominante; para interpelar la forma de comunicar y reestructurar los procesos comunicacionales.

Esta vertiente crítica europea incorpora en la Comunicación latinoamericana elementos esenciales para imaginar nuevas formas de organización de los sectores populares y su relación con diversas instancias, funciones y dispositivos (Foucault, 1978, p. 114). 
La sociedad democrática también se comprende en virtud a la complejidad de Latinoamérica, permeada por la vertiente dogmática, caracterizada por un proceso unidireccional de verter las ideas de las clases políticas dominantes (fuente) a un balde (medios de comunicación) que, a través de películas, telenovelas, libros, programas de radio y televisión, lanzan el balde sobre el receptor (población) con el fin de vaciar el contenido dentro de su cabeza (Berlo, 1984, p. 82).

Las particularidades socioeconómicas y políticas del continente constituyeron históricamente un quiebre teórico conceptual en la forma de comunicar y en la forma de realizar una gestión eficiente de la comunicación acorde con las realidades sociales que se demandaban y demandan. Sin embargo, la concepción tradicional de la Comunicación en Latinoamérica tiende en lo operativo, a emular la teoría de los efectos (Hernández, 1999, p. 178). En esta lógica existen trabajos destacados como el de Néstor García Canclini (5) desde el campo de la sociología (García, 1984, p. 69) cuyo aporte sustancial radica en la desmitificación del pueblo como masa eternamente oprimida e incapaz de participar en los procesos de construcción de hegemonía (Portantiero, 1978, p. 157) En su aporte teórico García Canclini logra apartarse del antagonismo polarizado de lo opresor-dominante y lo subalterno, logrando evidenciar fenómenos culturales mucho más complejos que los evidentes. De esta forma innovando un nuevo pensamiento latinoamericano inmerso en los estudios culturales y fenómenos propios de la región.

Esta evolución en la Comunicación trae consigo para Latinoamérica una nueva forma de entender la gestión comunicacional desde lo científico cuantitativo, otorgado por los teóricos pragmáticos, pasando por el pensamiento crítico europeo, hasta el propio desarrollo democrático latinoamericano con enfoques 
comunicacionales muy particulares y diferenciados con relación al mundo europeo y anglosajón tales como: el estudio de la ideología dominante, propiedad de los medios de comunicación, explotación de los trabajadores de la información y la comunicación, control de los medios, crítica de la libertad de prensa versus la libertad de empresa, mercantilización de la noticia, vínculos entre los medios y el poder; entre otros enfoques que plantean una comunicación horizontal (Beltrán, 1982, p. 62). Comunicología enfocada en la participación democrática, la interpelación a los tipos de democracias y a los tipos de desarrollo, y la constante preponderancia de la comunicación como un derecho al alcance de todos para su acceso, pero también desarrollo e intercambio bidireccional emisor-receptor en todos los niveles y dimensiones sociales.

De este fundamento teórico comunicacional se genera una gestión de la comunicación capaz de aglutinar los elementos ya mencionados de una forma ecléctica. De la corriente pragmática se parte del supuesto de la aplicación de un método científico en la Política y la Comunicación. Entendiendo que los impulsos pragmáticos generan revoluciones científicas (Kuhn, 1971, p. 97), con un conocimiento científico que se asienta en la lógica, ya que la ciencia es impensable sin las normas lógicas. Con la contrastación científica de la realidad política se generan diversas tácticas y estrategias comunicacionales para una participación política mucho más activa de la ciudadanía.

El conocimiento de los fundamentos, potencialidades, límites y enfoques de la teoría crítica, no debe ser concebido e interpretado como dogma, en virtud de que los dogmas no admiten críticas ni dudas. Una real participación política de múltiples sectores sociales en las decisiones sobre la implementación de políticas públicas, por ejemplo, debe saber comunicar y administrar el potencial 
dogmático de cualquier discurso político. El paradigma de la comunicación horizontal mencionando precedentemente, aplicado a la democracia debe reemplazar las verdades eternas o dogmas por hipótesis que deben estar siempre expuestas al escrutinio y a la posibilidad de ser refutadas.

En función a las teorías pragmáticas y críticas de la Comunicación, se entiende la gestión de la comunicación como el diálogo permanente concebido desde la prerrogativa del derecho a la participación, información y comunicación. El trabajo comunicacional debe someterse a parámetros científicos y considerar todas las hipótesis posibles, examinar los hechos desde todos los ángulos con sus multideterminaciones, sin rechazar ni descartar ninguna teoría, aunque contradiga la creencia a la cual se adscribe toda propuesta social, cultural, económica o política inicial.

Los comunicólogos tienden a delimitar los paradigmas que producen conocimientos, pero que a la vez limitan la posibilidad de comprender la realidad en su multiplicidad. En una gestión comunicacional eficiente se requiere de pensadores intrusos (Wagensberg, 2014, p. 52) con conocimientos de diversos paradigmas utilizados alternativamente según convenga el desarrollo de las múltiples propuestas que se generan desde las sociedades democráticas.

En determinado momento hipotético inicial de toda propuesta social se requerirán de los fundamentos científicos que permitan medir alcances y evaluar cuantitativamente aceptaciones hacia y desde la sociedad directamente participe e involucrada.

La gestión comunicacional en una primera etapa desarrollará a través de encuestas, grupos focales y entrevistas insumos comunicacionales que se interpretan a través del pragmatismo comunicacional. Para la construcción del 
discurso y el posicionamiento de temas que refuercen o interpelen el sentido común de la sociedad en favor del proyecto de trasformación social se requieren insumos de orden ideológico, herramientas y elementos que se desarrollan desde la Comunicación de la vertiente crítica.

Las sociedades latinoamericanas se desarrollan culturalmente a través de la conversación (Mora y Araujo, 2005, p. 115). Misma que debe ser fluida y constante involucrando a más ciudadanos comunes en temas antes reservados sólo para políticos o intelectuales. Con las mediaciones tecnológicas la opinión pública incluyó a toda la población transformando los valores y normas de la democracia y de las formas de comunicar. Es así que la participación de la ciudadanía en la elaboración, socialización y generación de nuevas lógicas sociales debe establecer canales de comunicación directa de ida y vuelta con inmediatez entre la propuesta social de transformación y la gente que se comunica e interactúa en espacios comunicacionales determinados.

Superada la comunicación unidireccional (Marcuse, 1964, p. 38) tanto emisores como receptores se encuentran en igualdad de condiciones en la generación de mensajes e incidencia comunicacional que pueden o no ejercer. Los flujos comunicacionales de inter-relaciones sociales deben entablarse en un ambiente familiar, receptivo, amigable y de constante interacción física, pero también virtual, misma que debe ser virtual humanizada, no automatizada ni automática.

\section{Formas de organización popular desde la Comunicación}

La Comunicación asume, entre muchos otros abordajes, el campo de la construcción de la hegemonía planteada por Antonio Gramsci, pero también las formas modernas de articulación social en base al consumo y las demandas 
sociales que generan una determinada organización popular. Un texto que permite matizar estas lógicas es el de Néstor García Canclini: Gramsci con Bourdieu. Hegemonía, consumo y nuevas formas de organización popular (García, 1984, p.77) en el mismo se propone un estudio más allá del positivismo estructuralista y la concepción funcionalista sobre los aparatos ideológicos, los mecanismos omnipotentes de dominación y la oposición entre lo hegemónico y lo subalterno (Althusser, 2016, p. 73).

Tres son los ejes temáticos abordados en el texto: la hegemonía, el consumo y las formas de organización de los sectores populares. La hegemonía (Portantiero, 1981, p. 81) se entiende en un plano diferenciado a la categoría de "dominación", una forma de apropiación del poder por un sector a partir de la administración y generación de consensos con los otros sectores de la sociedad. El consumo como los procesos sociales de apropiación de los productos en su condición inherente a la lucha de clases por participar en la distribución de los bienes y satisfacción de necesidades. $Y$ las formas de organización de los sectores populares como instancias, funciones y dispositivos (Foucault, Michel, 1978, p. 124).

Reiterando, el aporte sustancial del texto de García Canclini es la desmitificación del pueblo como masa eternamente oprimida incapaz de participar en los procesos de construcción de hegemonía. Su construcción teórica matiza el antagonismo polarizado de lo opresor-dominante y lo subalterno. El aporte se enmarca en la innovación de los estudios culturales que trazan líneas de interpretación y acción de los fenómenos culturales de características complejas a su presentación evidente.

A través de esa línea de estudio se evidencian insumos para la interpretación de realidades modernas fragmentadas y complejas que desarrollan lógicas de 
relacionamiento más allá de la polarización opresor-oprimido. Ya que en la construcción de la hegemonía no existen sectores de la sociedad predestinados o exclusivos para el ejercicio del poder, el consumismo, la concientización de la resistencia o para la existencia popular alternativa. Son los sectores populares los que legitiman un sistema hegemónico en base a pactos que otorgan prestaciones reciprocas. Esta línea de estudio ayuda a entender las composiciones políticas heterogéneas más complejas y preponderar la importancia de cada sector de la sociedad que no siempre se encuentra representado en un partido u organización política. Ayuda a entender que las sociedades modernas se organizan en base a intereses, aspiraciones y necesidades en un contexto multideterminado por factores no solamente económicos; sino también culturales, luchas de reivindicación y posición privilegiada en la construcción de los consensos sociales.

El consumo entendido desde los intereses del trabajador-consumidor con sus múltiples contradicciones evidencia no sólo la lucha por el poder, sino la apropiación de los significados y significantes culturales para luchar contra las formas de poder, de represión, de discriminación. Pero a la vez, en la cotidianidad, por la apropiación de los bienes y servicios. Esta forma el consumo pasa a constituirse en una articulación compleja entre lo ideológico, político y socioeconómico.

La movilización de los sectores populares no solamente se debe entender como manifestaciones de resistencia al poder desde una subalternidad, ya que las contradicciones sociales modernas vinculan y movilizan causas como la vivienda, acceso a la educación, atención médica, transporte, servicios básicos, calidad de vida; que se encuentran en el plano del consumo. 
El texto de García Canclini ayuda a entender también las reconfiguraciones sociales a partir de las acciones hegemónicas que pueden suscitar nuevos comportamientos. La construcción de un nuevo sentido común con propios hábitos, valores y subjetividades que se renuevan y posicionan en las sociedades.

La visión integradora, de la noción de hegemonía gramsciana y la categoría de "el habitus" (Bourdieu, 2000, p. 46), que realiza García Canclini brinda un panorama plural mucho más acorde al tiempo de organización fragmentada y de múltiples intereses que se presentan en la diversidad de los aspectos étnicos, sexuales, de consumo y representación política. El relacionamiento entre los sectores populares y las estructuras de poder, que no siempre devienen del Estado-Nación, compone la cultura moderna cotidiana con múltiples contradicciones y apartada de un carácter homogéneo, aglutinador o de cohesión social determinado. La pluralidad determinada por múltiples factores materiales y culturales abre el panorama de nuevas interpretaciones de la realidad social segmentada y generadora de nuevos paradigmas de hegemonía, consumo y organización.

Uno de esos paradigmas es la noción moderna de la superación de la teoría del Estado, tal cual se estructuró en los siglos pasados; por un nuevo paradigma planteado por Enrique Dussel (6) que refuerza la idea de las construcciones populares y plurales de Comunidad por sobre Estado como institución e instrumento irradiador de poder y control (Dussel, 2012, p.19).

Desde la doctrina decolonial Dussel plantea este paradigma de hegemonía, consumo y referencia popular con otros elementos políticos y filosóficos, pero todos transversalizados por la ética; para la construcción de poderes populares altamente legitimados por la propia población. Escenario utópico donde los 
aparatos de coerción y coacción se limitarían a su mínima expresión, quebrando con las instituciones autorreferenciales. Si se analiza en paralelo la propuesta de García Canclini y la de Enrique Dussel se puede arriban a una construcción popular que materialice la premisa constitucional boliviana de "vivir bien" (7) como paradigma civilizatorio alternativo y contrario a la construcción cultural occidental "american way of life".

\section{Conclusión}

El abordaje teórico de los enfoques comunicacionales permite identificar la ruta de toda estrategia comunicacional. Los elementos comunicacionales deben adecuarse a esa pre-determinación de la estrategia en función de la transformación de lo socialmente constituido. Todo tipo de abordaje teórico conceptual, diferente uno de otro como se precisó en el desarrollo, conlleva diferentes nociones básicas de orden analítico e interpretativo de la realidad social. El dilema comunicacional en la construcción de sentido común radica implícitamente en las nuevas formas de entender las transformaciones sociales a partir de la utilización de elementos comunicacionales diversos. Las sociedades democráticas latinoamericanas enfatizan el carácter plural de su composición, pero no los elementos diversos de tratamiento de sentidos, valores, premisas, discursos y acciones de cuestionamiento del sentido común imperante para su deconstrucción y reconfiguración en torno a valores democráticos devenidos de la construcción de consensos y replanteamientos de hegemonía, consumo y organización.

El cientista social Boaventura De Sousa Santos señala que la democracia actual es altamente antidemocrática ya que se vive en imaginarios democráticos en realidades cada vez más dictatoriales. Ante ese dilema el 
desafío de la comunicación estratégica es el de generar espacios de encuentro que impliquen acciones y nuevos sentidos compartidos, generar a partir de estrategias de comunicación dispositivos que conciban nuevos planos de interpretación política, económica, social y cultural. Organizar puntos de contacto para la generación de nuevas realidades a partir de la crítica y cuestionamiento del sentido común imperante.

Los elementos comunicacionales estratégicos deben plantear líneas concretas de transformaciones sociales a través de la generación de distintos espacios de diálogo, que, a la vez, generan horizontes de mayor complejidad a partir del apropiamiento e identificación con los derechos inherentes a la participación, información, comunicación, construcción de hegemonía, intereses de consumo en bienes y servicios, espacios de representación y organización. Las sociedades democráticas latinoamericanas se encuentran inmersas en el paradigma transformador de las condiciones sociales cotidianas; que se expresan en demandas, necesidades propias y urgentes en sintonía con el momento histórico determinado. La comunicación debe consensuar los dispositivos de fortalecimiento democrático y gobernabilidad popular; a través del diseño, gestión y evaluación de diferentes estrategias comunicacionales que consoliden espacios continuados de construcción de consensos.

El sentido común es mutante y complejo, es a la vez constructor del sentido de época y regulador del clima y humor social. La ciencia política, sociología y psicología atribuyen su deconstrucción y construcción únicamente a ciertas clases políticas detentadoras de los poderes económicos, ejecutivos, legislativos o judiciales. Pero la Comunicación construye sentido común todos los días a través de múltiples elementos comunicacionales, sincronizados 0 individuales. La lógica de toda estrategia comunicacional radica en sincronizar 
los elementos, tácticas y acciones en función de un objetivo, este debiera ser la construcción de un sentido común democrático arraigado, interiorizado, asumido y reproducido por una nueva sociedad consiente de la importancia de la comunicación para las transformaciones sociales.

Para la construcción del sentido común en sociedades democráticas se debe tomar en cuenta que no existen verdades inamovibles o inmutables en el tiempo, todo se somete a la sana crítica y a su contrastación científica. Los medios de comunicación y los políticos no son los únicos capaces de reconfigurar, criticar o construir sentido común. Con el surgimiento de las herramientas técnicas y tecnológicas de la modernidad toda la población en su conjunto es capaz de generar espacios de deconstrucción de valores, construcción de sentidos y generación de nuevas lógicas societales.

Un nuevo sentido común se genera a partir de nuevos actores sociales, de nuevos sentidos, nuevos discursos, nuevas lógicas, nuevas formas de organización a partir de las lógicas de consumo de bienes y servicios. Mientras la hegemonía se construye también genera un nuevo sentido de época, una nueva forma de ver e interpretar de forma dinámica la sociedad.

El sentido común de organización vertical y los acuerdos entre medios y políticos pierden cada día vigencia por las propias nuevas formas de organización popular transversalizadas por la tecnología. Gran parte de los miembros de la sociedad se encuentran en condiciones necesarias y suficientes para generar aristas de un nuevo sentido común, de nuevas lógicas y valores colectivos. La construcción de nuevos consensos se realiza todos los días y de todas las formas posibles abordando diversos elementos comunicacionales y mediados por los insumos tecnológicos modernos. 
Como la conversación, la construcción de hegemonía también se estimula a través de la generación de espacios. Para construir esos espacios de debe tener dominio de los abordajes comunicacionales y la utilización de los mejores elementos que proyecten una comunicación fluida y horizontal, articulando elementos emocionales, discursivos, educativos, de entretenimiento, subjetividades, ilusiones, deseos y proyecciones que se trabajan desde la Comunicación.

Los diferentes elementos comunicacionales en función a una gestión comunicacional efectiva deben partir de la premisa básica de que la Comunicación no se centra en la lógica de los sacrificios, sino en función de las distintas posibilidades y metas de transformación de la propia realidad social precedente. Las nuevas lógicas de organización que fortalecen las sociedades democráticas no se centran en dogmas, sino en causas colectivas. La racionalidad moderna y construcción de hegemonía se enmarcan en función de los cambios que se experimentan respecto a una situación anterior.

Los elementos comunicacionales deben ser seleccionados en función a un determinado abordaje. Posteriormente una adecuada gestión de la comunicación para la transformación social y construcción de un nuevo sentido común debe basarse en el diseño creativo que comprenda y atienda la reconfiguración de las lógicas de consumo y organización popular. Las sociedades democráticas son cada vez menos racionales y cada vez más emocionales, la construcción de subjetividad y la comunicación visual generan sentidos cada vez más complejos y completos, las percepciones democráticas en los últimos años son muy diferentes a las de los últimos siglos, por ende, todos esos elementos dinámicos y diversos deben tomarse en cuenta desde la 
Comunicación para replantear los paradigmas superestructurales de la sociedad que se quiere transformar.

Latinoamérica paulatinamente ha desarrollado desde sus diversos procesos políticos y comunicacionales una concepción de mundo con nuevos sentidos en la vida de los gobernados y gobernantes, además ha demostrado en los últimos 20 años procesos que desmitificaron las concepciones de posiciones perpetuas de subalternidad. Se han planteado paradigmas civilizatorios interesantes desde dos polos: la sociedad civil y la sociedad política. Este proceso de producción de un nuevo orden civilizatorio en el que cabe la pluriculturalidad e interculturalidad sigue en construcción entendiendo la heterogeneidad de las sociedades latinoamericanas antagónicas en muchos casos a las sociedades europeo continentales y anglosajonas. Latinoamérica continúa viviendo momentos orgánicos de construcción a partir de la gran política estatal pero también de las causas ciudadanas desde el plano de la sociedad civil. Los procesos políticos y comunicacionales no se entienden más a partir de dogmas o preceptos pre establecidos, rigen las lógicas emocionales e identitarias por sobre la racionalidad. Esos procesos de deconstrucción de las superestructuras en Latinoamérica se están dando a partir de la comunicación como elemento central condensador para interpretar la realidad social, plasmar estrategias desde la comunicación política y la praxis desde la ciudadanía quebrando con el monopolio de la generación de sentido común única y exclusivamente desde la sociedad política. Los emporios mediáticos han dejado de detentar el poder que los caracterizó en siglos pasados siendo cada vez más criticados, resistidos y refutados desde lógicas comunicacionales alternativas impulsadas por las nuevas tecnologías y redes sociales. Los partidos políticos han dejado de ser protagonistas constructores de ordenes 
sociales totalizantes acudiendo a colectivos ciudadanos movidos no por ideologías sino por causas (ambientalistas, animalistas, artísticas, etc.) reconfigurándose los sentidos de construcción de hegemonía que se disputa entre lo ciudadano y gubernamental (en todos sus niveles; central, departamental y municipal). La Comunicación dejó de ser accesoria para convertirse en una real fuente de interpretación de la realidad social.

\section{Bibliografía}

- Althusser, L. (2016). Ideología y aparatos ideológicos de Estado. España. Nueva Visión.

- Althusser, L. (1988). La filosofía como arma de la revolución. México. Pasado y Presente.

- Beltrán, L. (1982). Premisas, objetivos y métodos foráneos en la investigación sobre comunicación en América Latina. España. Editorial Gustavo Gili.

- Berlo, D. (1984). El proceso de la comunicación. Argentina. El ateneo.

- Bourdieu, P. (2000). Cuestiones de sociología. España. Akal.

- Dussel, E. (2012). ¿Estado o Comunidad? Bolivia. Grito del sujeto.

- Foucault, M. (1978). Microfísica del Poder. España. La Píqueta.

- García, N. (1984). Hegemonía, consumo y nuevas formas de organización popular. Revista Latinoamericana de Ciencias Sociales "Nueva Sociedad", pp.69-78.

- Hernández, M. (1999). Los efectos teoría y práctica. Trabajos prepublicados del $41^{\circ}$ Congreso de la API. Chile. Ponencias oficiales.

- Kuhn, T. (1971). La estructura de las revoluciones científicas. México. Fondo de Cultura Económica. 
- Marcuse, H. (1964). El hombre unidimensional. Estados Unidos. Beacon Press.

- Massoni, S. (2011). Comunicación estratégica Comunicación para la innovación. Rosario. Argentina. Homo Sapiens Ediciones.

- Mcquail, D. (1985). Introducción a la teoría de la comunicación de masas. Barcelona. España. Paidós.

- Mora Y Araujo, M. (2005). El poder de la conversación. Elementos para una teoría de la opinión pública. Argentina. La Crujía.

- Portantiero, J. (1978). Los usos de Gramsci. México. Folios.

- Wagensberg, J. (2014). El pensador intruso. España. Tusquets.

\section{Notas}

(1) Entendida como la matriz psicológica común en una sociedad construida en base a las múltiples exposiciones sociales, políticas, culturales y comunicacionales tácitas, incuestionadas, comúnmente aceptadas como lógicas y que rigen de forma automática el comportamiento y los esquemas societales.

(2) Artículo 1 de la Constitución Política del Estado Plurinacional de Bolivia.

(3) Los fundamentos jurídicos y constitucionales se encuentran en la primera parte de la Constitución Política del Estado, sobre las bases fundamentales del Estado, capítulo primero concerniente al modelo de Estado.

(4) Harold Lasswell, Charles Wright, Paul Lazarsfeld, Robert Merton, Melvin L. De Fleur entre sus máximos exponentes.

(5) Filósofo, sociólogo y crítico de arte argentino. Doctorado en Filosofía en las Universidades de La Plata y de París. 
(6) Enrique Domingo Dussel es un académico, filósofo, historiador y teólogo argentino, uno de los fundadores de la Filosofía de la liberación.

(7) Precepto ético-moral y paradigma de calidad de vida, que se menciona en la CPE de Bolivia dos veces en la parte introductoria de fundamentos constitucionales y en los artículos: 8 parágrafo I y II, 80 parágrafo I, 306 parágrafo I, III y artículo 313. 